\title{
Prevalence, species distribution and antimicrobial resistance patterns of methicillin-resistant staphylococci in Lithuanian pet animals
}

\author{
Modestas Ruzauskas ${ }^{1 *}$, Natacha Couto ${ }^{2}$, Sigita Kerziene ${ }^{3}$, Rita Siugzdiniene ${ }^{1}$, Irena Klimiene ${ }^{1}$, Marius Virgailis ${ }^{1}$ \\ and Constança Pomba²
}

\begin{abstract}
Background: The bacterial genus Staphylococcus consists of many species that causes infections in pet animals. Antimicrobial resistant staphylococci cause infections that are difficult to treat and they are important from the point of one health perspective. The aim of this study was to determine the prevalence of methicillin-resistant Staphylococcus (MRS) species, including methicillin-resistant S. aureus (MRSA) in diseased pet animals (Group A) and kennel dogs (Group B) in Lithuania and to characterize the isolates according to their antimicrobial resistance.

Results: Twenty-one MRS isolates were obtained from 395 clinical samples (5.3 \%; Cl 95 \% 3.5-8.0) of Group A animals. Sixteen, four and one isolates were from dogs, cats and a pet rabbit, respectively. The mecA gene was present in 20 isolates, whereas one isolate was positive for the mecC gene. Twenty-one MRS isolates (20.0\%; $\mathrm{Cl}$ $95 \%$ 13.5-28.6) were obtained from the vagina of female dogs $(n=105)$ (Group B). All isolates carried the mecA gene. Twelve MRS species were isolated of which $S$. pseudintermedius was the most common (18/42) followed by $S$. haemolyticus (8/42) and S. lentus (4/42). MRSA was not found. All MRS strains were susceptible to vancomycin, linezolid, daptomycin and quinupristin/dalfopristin. Resistance to tetracycline (16/21), clindamycin (15/21) and erythromycin (14/21) was the most common types of resistance in Group A animals. Three isolates also demonstrated resistance to rifampin. Resistance toward gentamicin (16/21), ciprofloxacin (15/21), macrolides (15/21) and tetracycline $(12 / 21)$ was the most common in kennel dogs (Group B). The most common genes encoding resistance to antimicrobials (excluding beta-lactams) in isolates from Group A pets were tetK (21/42), aph(3')-IIIa (11/42) and aac(6')-le-aph(2")-la (9/42).
\end{abstract}

Conclusions: A wide range of MRS species were found in pet animals in Lithuania. MRSA was not found.

Keywords: Staphylococcus, Methicillin-resistance, Kennels, Antimicrobial resistance, Pets, MecC

\section{Background}

Increasing amounts of antimicrobials, including critically and highly important antibiotics for humans (CHIAH), are used for treatment of pets. There are data showing that infections in dogs and cats often are caused by resistant bacteria [1]. Transmission of bacteria, particularly staphylococci, occurs between pets, owners, and veterinary staff, and the animals can act as reservoirs [1]. Methicillin-resistant Staphylococcus aureus (MRSA) is

\footnotetext{
* Correspondence: ruzauskas@lva.It

${ }^{1}$ Microbiology and Virology Institute, Lithuanian University of Health Sciences, Veterinary Academy, Mickeviciaus g. 9, LT44307 Kaunas, Lithuania Full list of author information is available at the end of the article
}

one of the most important bacteria causing infections in mammals. Companion animals, such as cats and dogs, are seldom colonized by MRSA but they can act as a reservoir [2-4]. A recent study by Harrison et al. [2] found that a population of an important, globally disseminated lineage of MRSA can infect both humans and companion animals without undergoing host adaptation. More recently numerous of MRSA lineages with a novel $m e c A$ gene homologue, named $m e c C$, were identified. These are capable of colonizing and infecting a broad range of mammalian and avian species $[3,5]$. In the past years, the $m e c C$ gene was found in other methicillinresistant Staphylococcus (MRS) species as well [6]. 
S. pseudintermedius is another important opportunistic pathogen of companion animals [7]. This species carries different genes that encode resistance to antimicrobials [8]. A study performed by Laarhoven et al. [9] demonstrated that similar or indistinguishable methicillinresistant S. pseudintermedius (MRSP) isolates occur in humans, contact animals and environmental samples within the same households [9]. Recently MRSP clonal strains have become widely spread in Europe and North America [8]. For instance, the first 13 isolates of MRSP in dogs in Sweden were reported in 2006. Since then, the occurrence of MRSP in Sweden has been reported yearly: in 2007 and 2008, more than 180 MRSP isolates were confirmed, whereas 33 isolates were detected in 2013 [10]. S. pseudintermedius is a leading cause of skin, ear and post-operative wound infections $[11,12]$.

Another coagulase-positive Staphylococcus species prevalent in companion animals associated with frequent resistance to methicillin is $S$. schleiferi $[12,13]$. Very recently, methicillin-resistant S. schleiferi was isolated from dogs, their owners and veterinarians [14]. Coagulasenegative MRS species such as S. epidermidis, S. haemolyticus, S. lentus, S. sciuri, and S. simulans have been isolated from companion animals as well [15-17].

Studies on MRS prevalence in companion animals in different European countries have been reported [7, 18, 19]. Knowledge on the occurrence of MRS in the Baltic States is sparse. The aim of this study was to investigate the occurrence of MRS species, in particular MRSA, in diseased pet animals and kennel dogs in Lithuania and to characterize the isolates according to their antimicrobial resistance, particularly to CHIAH.

\section{Methods}

\section{Study design, animals and sampling}

In 2012-2014 clinical samples were collected from 395 pet animals admitted to small animal clinics in Lithuania (Group A). Only samples sent by veterinary surgeons were included to the study. The samples were taken from diseased animals (dogs, cats, pet rabbits, guinea pigs and prairie dogs) with various clinical conditions: skin infections and wounds $(n=300)$, otitis $(n=45)$, gastrointestinal- $(n=25)$ and respiratory $(n=25)$ tract infections. Additional sampling was performed on kennels with reproductive disorders (pyometra, vaginitis, infertility, preterm birth, abortions) (Group B). Vaginal swabs from 105 bitches from 32 kennels were collected to estimate the occurrence of MRS in this subpopulation. In both studies samples were collected by a veterinary surgeon using sterile Amies media swabs (Liofilchem, Roseto, Italy) for the screening purposes. Samples were delivered to the laboratory during the same day. This study involved animals from the six counties out of 10 in Lithuania.

\section{Bacteriological analyses}

Although all clinical samples underwent diagnostic routine bacteriological culturing, the aim of this particular study was MRS screening. Therefore, swab material was inoculated onto Mannitol Salt Agar supplemented with $4 \mathrm{mg} / \mathrm{L}$ cefoxitin (Sigma-Aldrich, Hamburg, Germany country). One colony per sample was selected for further testing unless colonies were observed that differed in the fermentation of mannitol. Two colonies were taken in those cases and treated as two different isolates. Presumptive identification of staphylococci was based on the growth and morphological characteristics, catalase production, Gram-staining and susceptibility to furazolidone. Presumptive species identification was based on pigment and coagulase production, presence of protein A and clumping factor as well as on biochemical properties detected by RapID Staph Plus identification system (Thermo Scientific, Lenexa, USA). If identification reliability according manufacturer's software was less than $95 \%$ of species probability, Matrix-Assisted Laser Desorption/Ionization Time-of-Flight (MALDI-TOF) analysis (VITEK $^{\ominus}$ MS, Biomérieux, France) was used as described previously [20].

\section{Molecular analysis}

DNA for molecular analysis was obtained after bacterial lysis according to the extraction protocol prepared by the Community Reference Laboratory for Antimicrobial Resistance with slight modifications [21]. Briefly, cultures were grown on a Mueller Hinton Agar (Liofilchem, Roseto, Italy) for $24 \mathrm{~h}$ and afterwards a loopful of colonies was taken from the surface of the agar and transferred to phosphate buffered saline ( $\mathrm{pH}$ 7.3). The content was centrifuged for $5 \mathrm{~min}$. The supernatant was discarded and the pellet was re-suspended in Tris-EDTA (TE) buffer. The suspension was heated using a thermomixer at $100{ }^{\circ} \mathrm{C}$ for $10 \mathrm{~min}$. Boiled suspension was transferred directly on ice and diluted by 1:10 in TE.

Polymerase chain reaction (PCR) was used for the detection/confirmation of S. aureus and S. pseudintermedius using species-specific primers as described previously $[21,22]$.

\section{Antimicrobial susceptibility testing}

Antimicrobial susceptibility testing was performed using the broth microdilution method. Sensititre ${ }^{\circledR}$ plates and the ARIS 2X automated system (Thermo Scientific, Ashford, UK) were used with the following antimicrobials: clindamycin, erythromycin, gentamicin, tetracycline, daptomycin, ciprofloxacin, sulfamethoxazole/trimethoprim, linezolid, quinupristin/dalfopristin, vancomycin, and rifampin. Interpretation of results was carried-out using the manufacturer's software $\left(\mathrm{SWIN}^{\oplus}\right)$ adapted to clinical breakpoints of the European Committee on 
Antimicrobial Susceptibility Testing (EUCAST). Strains were considered as resistant if minimum inhibitory concentrations (MIC's) of antimicrobials were $>2 \mathrm{mg} / \mathrm{L}$ for erythromycin, tetracycline and quinupristin/dalfopristin; $>0.5 \mathrm{mg} / \mathrm{L}$ for clindamycin and rifampin; $>1 \mathrm{mg} / \mathrm{L}$ for daptomycin, gentamicin and ciprofloxacin; $>4 \mathrm{mg} / \mathrm{L}$ for linezolid, sulfamethoxazole/trimethoprim and vancomycin. As there are no clinical breakpoints set for vancomycin and gentamicin to S. pseudintermedius, we used the breakpoints as for $S$. aureus, i.e., resistant $>2 \mathrm{mg} / \mathrm{L}$ for vancomycin and $>1 \mathrm{mg} / \mathrm{L}$ for gentamicin. The quality control strain S. aureus ATCC 29213 was included in each assay.

Detection of genes encoding antimicrobial resistance was performed according previously described protocols. The tested genes included mecA [21], mecC [23], blaZ [24] (beta-lactams), tet $(\mathrm{K})$, tet $(\mathrm{M})$ [25] (tetracycline), $\operatorname{erm}(\mathrm{A}), \operatorname{erm}(\mathrm{C})$ [26], $\operatorname{msr}(\mathrm{A})$ (macrolides and streptogramins) [27], aac(6')-Ie-aph(2")-Ia and aph(3')-IIIa (aminoglycosides) [27].

\section{Data analysis}

MRS occurrence in clinical specimens and in kennel specimens were calculated by dividing the number of MRS positive specimens by the total number of investigated specimens by group (n/N, \%). For percentage estimates, Wilson (Score) $95 \%$ confidence intervals (CI $95 \%$ ) were calculated. MRS occurrence was given by animal species as well. Antimicrobial resistance rates for each tested antimicrobials were given as numbers of resistant per total number of MRS isolates. MRS occurence dependence on the kennel size (number of breeding bitches in kennel) was assessed using logistic regression analysis. Statistical analysis was performed using "IBM SPSS Statistics 20" package. Results were considered statistically significant if $P<0.05$.

\section{Results \\ MRS occurrence and distribution \\ Group A}

Twenty-one MRS isolates were obtained from the 395 animals tested (5.3\%; CI $95 \%$ 3.5-8.0). These included 16 dog isolates (4.6\%; CI $95 \%$ 2.9-7.4), 4 cat isolates (10.0\%; CI $95 \%$ 4.0-23.1) and 1 rabbit isolate (Table 1).

All MRS isolates were resistant to oxacillin and carried mec genes. The mecA gene was present in 20 isolates whereas one isolate was positive for the $\mathrm{mecC}$ gene. This isolate was obtained from the nostril of a 6-year-old pet rabbit previously treated with antimicrobials and was identified as S. saprophyticus using MALDI-TOF analysis. The species of MRS isolates are presented in Table 2.

The most frequent location of MRS isolation was the skin $(n=8)$ including cases of pyoderma $(n=5)$ and infected wounds $(n=2)$. Four isolates were obtained from the respiratory tract; but only one animal had a severe
Table 1 Occurrence of methicillin-resistant staphylococci (MRS) in Group A and B animals

\begin{tabular}{lllllll}
\hline Study & Animal species & $\begin{array}{l}\text { Number } \\
\text { of animals } \\
\text { tested }\end{array}$ & $\begin{array}{l}\text { Number } \\
\text { of MRS } \\
\text { isolates }\end{array}$ & $\begin{array}{l}\text { Percent } \\
\text { of MRS } \\
\text { isolates }\end{array}$ & Cl 95 \% \\
\hline Group A & Dogs & 345 & 16 & 4.6 & 2.9 & 7.4 \\
& Cats & 40 & 4 & 10.0 & 4.0 & 23.1 \\
& Other & 10 & 1 & 10.0 & 1.8 & 40.4 \\
& Total & 395 & 21 & 5.3 & 3.5 & 8.0 \\
Group B & Dogs (bitches) & 105 & 21 & 20.0 & 13.5 & 28.6 \\
\hline
\end{tabular}

Group A consisted of 395 animals

Group B consisted of 105 animals

respiratory infection (haemorrhagic pneumonia). One MRS isolate was obtained from an ear and one from an alimentary tract

\section{Group B}

Twenty-one MRS isolates were obtained from the 105 tested dogs (20.0\%; CI $95 \%$ 3.5-8.0) (Table 1). All of them carried the mecA gene. Logistic regression analysis revealed that increase of the kennel size by one bitch increased the odds of the occurrence of MRS by 1.125 times $(95 \%$ CI $1.041-1.215 ; p<0.01)$. The highest statistically significant differences were obtained when large kennels ( $\geq 6$ dogs) were compared to small kennels ( $\leq 5$ dogs); odds to find MRS increased 10.1 times with increased kennel size (95\% CI 3.428-30.04; $P<0.001$ ).

A wide range of MRS species was detected in both Group A and B animals (Tables 2 and 3). S. pseudintermedius was the most common $(8 / 21$ and $10 / 21$ isolates in Groups A and B, respectively). S. haemolyticus occurred more common in Group B (7/21) than in Group A animals (1/21). MRSA was not found at all.

\section{Data on antimicrobial susceptibility Group A}

The antimicrobial susceptibility data and the genes encoding resistance in the MRS isolates are presented in Table 2. All strains were susceptible to vancomycin, linezolid, daptomycin and quinupristin/dalfopristin. Three isolates demonstrated resistance to rifampin. Resistance to ciprofloxacin was infrequent as only two isolates from Group A animals were resistant. Sixteen isolates demonstrated resistance to tetracycline and carried the tet $(\mathrm{K})$ $(n=9)$, tet $(\mathrm{M})(n=3)$ or both $(n=1)$ genes. Fourteen isolates were resistant to erythromycin and 15 to clindamycin. The isolates carried the genes $\operatorname{erm}(\mathrm{A}), \operatorname{erm}(\mathrm{C})$ and $m s r(\mathrm{~A})$ encoding macrolides methyltransferases and those genes were equally distributed among the isolates. Four isolates were resistant to gentamicin with attribution to the genes encoding production of (acethyl)phosphotranspherases $\operatorname{aac}\left(6^{\prime}\right)-\operatorname{Ie}-\operatorname{aph}\left(2^{\prime \prime}\right)-I a(n=2)$ and $\operatorname{aph}\left(3^{\prime}\right)$ IIIa $(n=3)$. 
Table 2 Distribution and susceptibility profiles of methicillin-resistant Staphylococcus isolates obtained from Group A pets $(n=21)$

\begin{tabular}{|c|c|c|c|c|c|c|c|c|c|c|}
\hline \multirow[t]{2}{*}{ Species } & \multicolumn{7}{|c|}{$\begin{array}{l}\text { Antimicrobial susceptibility profile }{ }^{1} \text { and clinical breakpoints } \\
(>\mathrm{mg} / \mathrm{L})\end{array}$} & \multirow[t]{2}{*}{ Resistance genes } & \multirow{2}{*}{$\begin{array}{l}\text { No.of } \\
\text { isolates } \\
\text { with this } \\
\text { type }\end{array}$} & \multirow[t]{2}{*}{$\begin{array}{l}\text { Animal } \\
\text { species }\end{array}$} \\
\hline & Tet (2) & Ery (2) & Cli (0.5) & SXT (4) & Cip (1) & $\operatorname{Rif}(0.5)$ & Gen (1) & & & \\
\hline \multirow[t]{8}{*}{ S. pseudintermedius } & $\mathrm{R}$ & $\mathrm{R}$ & $\mathrm{R}$ & $\mathrm{s}$ & $\mathrm{s}$ & S & $\mathrm{s}$ & mecA, blaZ, tetk, erm(C) & 1 & Cat \\
\hline & $\mathrm{R}$ & $\mathrm{R}$ & $\mathrm{R}$ & $\mathrm{R}$ & $S$ & $\mathrm{R}$ & $\mathrm{S}$ & mecA, blaZ, tetK, msr(A) & 1 & Cat \\
\hline & $\mathrm{R}$ & $\mathrm{S}$ & $\mathrm{S}$ & $\mathrm{R}$ & $\mathrm{S}$ & S & S & mecA, blaZ, tetK & 1 & Cat \\
\hline & $\mathrm{R}$ & $\mathrm{R}$ & $\mathrm{R}$ & $\mathrm{R}$ & $\mathrm{R}$ & S & $S$ & $\operatorname{mec} A, \operatorname{blaZ}, \operatorname{tet} M, \operatorname{erm}(A), \operatorname{msr}(A)$ & 1 & Dog \\
\hline & $\mathrm{R}$ & $\mathrm{R}$ & $\mathrm{R}$ & S & S & S & $\mathrm{R}$ & $\begin{array}{l}\text { mecA, blaZ, tetK, aac }\left(6^{\prime}\right)-l e-a p h\left(2^{\prime \prime}\right)-l a, \\
\operatorname{aph}\left(3^{\prime}\right)-I I I a, \operatorname{erm}(A)\end{array}$ & 1 & Dog \\
\hline & $\mathrm{R}$ & $\mathrm{R}$ & $\mathrm{R}$ & $\mathrm{R}$ & $S$ & $\mathrm{R}$ & $\mathrm{S}$ & mecA, blaZ, tetK, tetM, erm(C) & 1 & Dog \\
\hline & S & $\mathrm{R}$ & $\mathrm{R}$ & $\mathrm{S}$ & $\mathrm{S}$ & S & $S$ & mecA, blaz & 1 & Dog \\
\hline & $\mathrm{R}$ & $\mathrm{R}$ & $\mathrm{R}$ & $S$ & $\mathrm{~S}$ & S & S & mecA, blaZ, tetK, erm $(A)$ & 1 & Dog \\
\hline \multirow[t]{6}{*}{ S. haemolyticus } & $\mathrm{R}$ & $\mathrm{R}$ & $\mathrm{R}$ & $\mathrm{R}$ & $\mathrm{S}$ & S & $\mathrm{R}$ & mecA, blaZ, tetK, aac(6')-le-aph(2")-la, $\operatorname{msr}(A)$ & 1 & Cat \\
\hline & S & $\mathrm{R}$ & $\mathrm{R}$ & $\mathrm{S}$ & $\mathrm{R}$ & S & S & mecA, blaZ, erm(A) & 1 & Dog \\
\hline & $\mathrm{R}$ & $\mathrm{R}$ & $\mathrm{R}$ & $\mathrm{R}$ & $S$ & S & S & $\operatorname{mec} A, \operatorname{blaZ}, \operatorname{tet} M, \operatorname{msr}(A), \operatorname{erm}(A)$ & 2 & Dog \\
\hline & S & $\mathrm{S}$ & $\mathrm{R}$ & $\mathrm{S}$ & $\mathrm{S}$ & S & S & mecA, blaz & 1 & Dog \\
\hline & $\mathrm{R}$ & $\mathrm{R}$ & $\mathrm{R}$ & $S$ & $\mathrm{~S}$ & S & $\mathrm{R}$ & mecA, blaZ, tetK, aph(3')-IIIa, erm(C) & 1 & Dog \\
\hline & $\mathrm{R}$ & $\mathrm{R}$ & $\mathrm{R}$ & $\mathrm{S}$ & $\mathrm{S}$ & S & $S$ & mecA, blaZ, tetM & 1 & Dog \\
\hline S. lentus & $\mathrm{R}$ & $\mathrm{S}$ & S & $S$ & $S$ & S & S & mecA, blaZ, tetK & 1 & Dog \\
\hline S. sciuri & $\mathrm{R}$ & $\mathrm{R}$ & $\mathrm{R}$ & $\mathrm{S}$ & $\mathrm{S}$ & $\mathrm{R}$ & $S$ & mecA, blaZ, tetK & 1 & Dog \\
\hline S. epidermidis & $\mathrm{R}$ & $\mathrm{S}$ & S & $\mathrm{S}$ & $\mathrm{S}$ & S & S & mecA, blaz, tetK & 1 & Dog \\
\hline S. equorum & S & $\mathrm{S}$ & S & $\mathrm{S}$ & $\mathrm{S}$ & S & $\mathrm{R}$ & mecA, aph(3')-IIIa & 1 & Dog \\
\hline S. capitis & $\mathrm{R}$ & $S$ & S & $\mathrm{R}$ & $S$ & S & S & mecA, tetk & 1 & Dog \\
\hline S. saprophyticus & S & $S$ & S & $S$ & $S$ & S & S & mecc, blaz & 1 & Pet rabbit \\
\hline
\end{tabular}

${ }^{1}$ All isolates were oxacillin-resistant

$S$ - susceptible; R - Resistant

Tet - tetracycline, Ery - erythromycin, Cli - clindamycin, SXT - sulfamehoxazole/trimethoprim, Cip - ciprofloxacin, Rif - rifampin, Gen - gentamicin

\section{Group B}

The data on antimicrobial susceptibility and genes encoding resistance of MRS isolated in Group B dogs are presented in Table 3. Sixteen isolates were resistant to gentamicin and 15 to ciprofloxacin. Fifteen isolates were resistant to macrolides and clindamycin with highest distribution of $m s r(\mathrm{~A})$ gene $(n=7)$, rather than $\operatorname{erm}(\mathrm{A})$ $(n=3)$ and $\operatorname{erm}(\mathrm{C})(n=3)$.

\section{Discussion}

The study revealed that MRS are present in Lithuanian pet animals. The total number of positive samples/animals was $5.3 \%$ in Group A animals and $20 \%$ in Group B dogs, respectively. We detected 12 MRS species. The most frequently isolated species was $S$. pseudintermedius, which is known to be prevalent in dogs and cats [7, 9], followed by S. haemolyticus and S. lentus. S. haemolyticus is known as an important human pathogen and carrier of methicillinresistance genes [28]. Data on the occurrence of this species in dogs are still scarce. Van Duijkeren et al. [15] found four isolates of methicillin-resistant S. haemolyticus among 11 multidrug-resistant staphylococci isolated from dogs and cats. S. lentus is known as a colonizer in several animal species. It has commonly been isolated from foodproducing animals, including poultry [29], cattle and sheep [30], minks [31], but is rarely associated with infections in humans [32-34]. Recently methicillin-resistant strains of S. lentus were isolated from dogs [17]. Although we used selective medium supplemented with $4 \mathrm{mg} / \mathrm{L}$ cefoxitin, which is regarded as an appropriate medium for MRSA isolation, including low-level resistant strains [34], MRSA was not found. In Lithuania, four MRSA isolates were recently isolated from pigs on a single farm, although no MRSA was found in other food-producing animal species and horses [35], so MRSA occur although not detected in the investigated populations of pet animals.

Different species of MRS were obtained in this study using cefoxitin-supplemented medium, although it is suggested that oxacillin-supplemented media are more suitable for the detection of methicillin-resistance in $S$. pseudintermedius [36]. Thus, the number of isolates obtained in our study is probably underestimated and may have been higher if an oxacillin-supplemented medium had been used for the initial isolation of MRS. 
Table 3 Distribution and susceptibility profiles of methicillin-resistant Staphylococcus isolates obtained from Group B dogs ( $n=21)$

\begin{tabular}{|c|c|c|c|c|c|c|c|c|c|c|}
\hline \multirow[t]{2}{*}{ Species } & \multicolumn{7}{|c|}{$\begin{array}{l}\text { Antimicrobial susceptibility profile }{ }^{1} \text { and clinical breakpoints } \\
(>\mathrm{mg} / \mathrm{L})\end{array}$} & \multirow[t]{2}{*}{ Resistance genes } & \multirow{2}{*}{$\begin{array}{l}\text { No.of } \\
\text { isolates } \\
\text { with this } \\
\text { type }\end{array}$} & \multirow[t]{2}{*}{ Kennel } \\
\hline & Tet (2) & Ery (2) & Cli (0.5) & SXT (4) & Cip (1) & $\operatorname{Rif}(0.5)$ & Gen (1) & & & \\
\hline \multirow[t]{8}{*}{ S. pseudintermedius } & $\mathrm{R}$ & $\mathrm{R}$ & $\mathrm{R}$ & $\mathrm{S}$ & $\mathrm{R}$ & $\mathrm{S}$ & $\mathrm{R}$ & 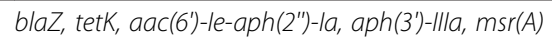 & 2 & 1,1 \\
\hline & $\mathrm{R}$ & $\mathrm{R}$ & $\mathrm{R}$ & $\mathrm{S}$ & S & S & $\mathrm{R}$ & blaZ, tetK, aph(3')-IIIa, $\operatorname{msr}(A)$ & 2 & $\|\|$, \\
\hline & $\mathrm{R}$ & S & $\mathrm{S}$ & $S$ & S & S & $S$ & blaZ, tetK & 1 & III \\
\hline & $\mathrm{R}$ & S & $\mathrm{S}$ & $\mathrm{s}$ & $\mathrm{R}$ & S & $\mathrm{S}$ & blaZ, tetK & 1 & III \\
\hline & $S$ & $\mathrm{R}$ & $\mathrm{R}$ & $S$ & S & S & $\mathrm{R}$ & blaZ, aph(3')-IIla, ermC & 1 & IV \\
\hline & $\mathrm{S}$ & $\mathrm{R}$ & $\mathrm{R}$ & $\mathrm{S}$ & $\mathrm{R}$ & $\mathrm{R}$ & $\mathrm{R}$ & 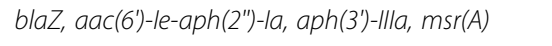 & 1 & V \\
\hline & $S$ & $\mathrm{R}$ & $\mathrm{R}$ & $\mathrm{S}$ & $\mathrm{R}$ & S & $\mathrm{R}$ & blaZ, erm(A) & 1 & $\mathrm{Vl}$ \\
\hline & $\mathrm{R}$ & $\mathrm{R}$ & $\mathrm{R}$ & S & $\mathrm{R}$ & S & $\mathrm{R}$ & blaZ, tetM, aph(3')-IIIa, msr(A) & 1 & VII \\
\hline \multirow[t]{2}{*}{ S. lentus } & $\mathrm{R}$ & S & S & $S$ & $\mathrm{R}$ & S & $S$ & tetK & 1 & III \\
\hline & $\mathrm{R}$ & $\mathrm{R}$ & $\mathrm{R}$ & $\mathrm{S}$ & $\mathrm{R}$ & $S$ & $\mathrm{R}$ & blaZ, tetM, aac(6')-le-aph(2")-la, erm(A) & 2 & 1,1 \\
\hline S. sciuri & $\mathrm{S}$ & $\mathrm{R}$ & $\mathrm{R}$ & $\mathrm{R}$ & $\mathrm{R}$ & S & $\mathrm{R}$ & 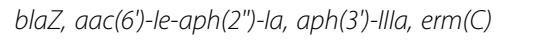 & 1 & । \\
\hline S. felis & $S$ & S & $S$ & $S$ & S & S & $\mathrm{S}$ & blaz & 1 & VIII \\
\hline S. epidermidis & $\mathrm{S}$ & S & $\mathrm{S}$ & $S$ & $\mathrm{R}$ & S & $\mathrm{R}$ & blaz & 1 & $\|$ \\
\hline S. xylosus & $\mathrm{S}$ & $S$ & $\mathrm{~S}$ & $\mathrm{~S}$ & $\mathrm{R}$ & $S$ & $\mathrm{~S}$ & - & 1 & $\|$ \\
\hline S. haemolyticus & $\mathrm{R}$ & $\mathrm{R}$ & $\mathrm{R}$ & $\mathrm{S}$ & $\mathrm{R}$ & S & $\mathrm{R}$ & blaZ, tetK, $\operatorname{aac}\left(6^{\prime}\right)-l e-a p h\left(2^{\prime \prime}\right)-1 a, \operatorname{erm}(C), \operatorname{msr}(A)$ & 1 & । \\
\hline S. chromogenes & $S$ & $\mathrm{R}$ & $\mathrm{R}$ & $S$ & $\mathrm{R}$ & S & $\mathrm{R}$ & - & 1 & IX \\
\hline S. schleiferi & $\mathrm{R}$ & $\mathrm{R}$ & $\mathrm{R}$ & $\mathrm{S}$ & $\mathrm{R}$ & S & $\mathrm{R}$ & tetK, tetM, aph(3')-IIIa, erm(C) & 1 & । \\
\hline S. capitis & $\mathrm{S}$ & $\mathrm{R}$ & $\mathrm{R}$ & $\mathrm{R}$ & $\mathrm{s}$ & $\mathrm{R}$ & $\mathrm{R}$ & blaZ, aac(6')-le-aph(2")-la & 1 & I \\
\hline
\end{tabular}

${ }^{1}$ All isolates were oxacillin-resistant

$\mathrm{S}$ - susceptible; R - Resistant

Tet - tetracycline, Ery - erythromycin, Cli - clindamycin, SXT - sulfamehoxazole/trimethoprim, Cip - ciprofloxacin, Rif - rifampin, Gen - gentamicin

All isolates obtained in this study were susceptible to the latest classes of antibiotics used exclusively in humans (lipopeptides, oxazolidinones, streptogramins) as well as to vancomycin. Resistance to rifampin was detected in four MRSP isolates although this antibiotic is not used for animals in Lithuania. Resistance of MRS isolates to other CHIAH was high: 15/21 of isolates from Group B dogs were resistant toward fluoroquinolones. There are no reliable data on the use of fluoroquinolones in Lithuanian animals, but it is known that poultry products as well as products of other food producing animals species are highly contaminated with fluoroquinolone-resistant bacteria [37, 38]. Resistance to gentamicin was found at a high rate as well. The genes encoding resistance to aminoglycosides $a a c\left(6^{\prime}\right)-I e-\operatorname{aph}\left(2^{\prime \prime}\right)-I a$ and $\operatorname{aph}\left(3^{\prime}\right)$-IIIa were detected in this study. These genes were recently found in staphylococci isolated from companion animals in other countries, as well as in enterococci isolated from diseased cows, pigs and poultry in Lithuania [7, 39].

The tet $(\mathrm{K})$ and tet $(\mathrm{M})$ genes were found in tetracyclineresistant isolates as also found by others $[8,40]$. $\operatorname{Erm}(\mathrm{A}, \mathrm{C})$ and $m s r(\mathrm{~A})$ genes encoding resistance to macrolides and clindamycin were detected with the highest prevalence of $m s r(\mathrm{~A})$, particularly in the isolates from Group B dogs. Forty-one out of 42 isolates from both groups harboured the mecA gene, whereas $m e c C$ gene was detected in one $S$. saprophyticus isolate. This gene was previously found almost exclusively in MRSA isolates. To the best of our knowledge, the $\operatorname{mecC}$ gene has only been found in S. saprophyticus in one case previously [41]. The isolate obtained by us was susceptible to all antimicrobials tested, except penicillin and oxacillin.

A high prevalence of MRS was found in Group B dogs. MRS present in the vagina may be transmitted to the environment, including surface of housewares. Moreover, breeding bitches pose a risk of transmitting MRS to their offspring, their owners and other animals.

MRS were mostly found in larger kennels ( $\geq 6$ dogs) suggesting that increased population size is a risk factor for carriage of MRS.

The few S. pseudintermedius and S. lentus isolates had the same antimicrobial susceptibility profiles indicating a possible clonal spread. Isolates with similar susceptibility profiles originated from the same kennels. MRS from different kennels differ in their susceptibility profiles thus demonstrating variety among strains.

\section{Conclusions}

A range of MRS species were found in diseased pet animals in Lithuania with a prevalence of $5.3 \%$. MRSA were 
not found. S. pseudintermedius was the most common MRS species but attention should also be paid to $S$. haemolyticus and S. lentus. Breeding kennels, particularly keeping 6 or more female dogs were commonly infected with MRS. Staphylococci isolated from Lithuanian pets remain susceptible to antibiotics authorized exclusively for treatment of humans.

\begin{abstract}
Abbreviations
CHIAH: Critically and highly important antibiotics for humans; MALDI-TOF: Matrix-Assisted Laser Desorption/lonization Time-of-Flight analysis; MIC: Minimum inhibitory concentration; MRS: Methicillin-resistant Staphylococcus: MRSA: Methicillin-resistant Staphylococcus aureus; MRSP: Methicillin-resistant Staphylococcus pseudintermedius; PCR: Polymerase chain reaction.
\end{abstract}

\section{Competing interests}

The authors declare that they have no competing interests.

\section{Authors' contributions}

MR, MV and NC designed the sampling protocol and selected methods; MR, RS, IK and MV performed bacteriological analyses and molecular testing; SK performed statistical analysis; MR, NC and CP conceived the study and drafted the manuscript. All authors contributed and approved the submitted manuscript.

\section{Acknowledgements}

These studies were funded by grants (MIP-061/2012; MIP-075/2013) from the Research Council of Lithuania.

\section{Author details}

${ }^{1}$ Microbiology and Virology Institute, Lithuanian University of Health Sciences, Veterinary Academy, Mickeviciaus g. 9, LT44307 Kaunas, Lithuania. ${ }^{2}$ Laboratory of Antimicrobial and Biocide Resistance, Faculty of Veterinary Medicine, University of Lisbon, Avenida da Universidade Técnica, 1300-477 Lisbon, Portugal. ${ }^{3}$ Department of Mathematics, Physics and Biophysics, Veterinary Academy, Lithuanian University of Health Sciences, Mickeviciaus g. 9, LT44307 Kaunas, Lithuania.

\section{Received: 17 September 2014 Accepted: 29 May 2015}

Published online: 02 June 2015

\section{References}

1. Lloyd DH. Reservoirs of antimicrobial resistance in pet animals. Clin Infect Dis. 2007;45 Suppl 2:148-52.

2. Harrison EM, Weinert LA, Holden MT, Welch JJ, Wilson K, Morgan FJ, Harris SR, Loeffler A, Boag AK, Peacock SJ, Paterson GK, Waller AS, Parkhill J, Holmes MA: A shared population of epidemic methicillin-resistant Staphylococcus aureus 15 circulates in humans and companion animals. mBio 2014, 5:e00985-13.

3. Walther B, Wieler LH, Vincze S, Antao EM, Brandenburg A, Stamm I, et al. MRSA variant in companion animals. Emerg Infect Dis. 2012;18:2017-20.

4. Loeffler A, Pfeiffer DU, Lindsay JA, Magalhaes RJ, Lloyd DH. Prevalence of and risk factors for MRSA carriage in companion animals: a survey of dogs, cats and horses. Epidemiol Infect. 2011;139:1-10.

5. Paterson GK, Larsen AR, Robb A, Edwards GE, Pennycott TW, Foster G, et al. The newly described mecA homologue, mecA LGA251, is present in methicillin-resistant Staphylococcus aureus isolates from a diverse range of host species. J Antimicrob Chemother. 2012;67:2809-13.

6. Becker K, Ballhausen B, Köck R, Kriegeskorte A: Methicillin resistance in Staphylococcus isolates: The "mec alphabet" with specific consideration of mecC, a mec homolog associated with zoonotic S. aureus lineages. Int J Med Microbiol, 304:394-804.

7. Van Duijkeren E, Boudewijn C, Greko C, Moreno M, Pomba C, Pyorala S, et al. Review on methicillin-resistant Staphylococcus pseudintermedius. J Antimicrob Chemother. 2011;66:2705-14.

8. Perreten V, Kadlec K, Schwarz S, Grönlund-Andersson U, Finn M, Greko C et al. Clonal spread of methicillin-resistant Staphylococcus pseudintermedius in Europe and North America: an international multicentre study. J Antimicrob Chemother. 2010;65:1145-54.
9. Laarhoven LM, de Heus P, van Luijn J, Duim B, Wagenaar JA, van Duijkeren E. Longitudinal study on methicillin-resistant Staphylococcus pseudintermedius in households. PLoS One. 2011;6, e27788.

10. Bengtsson B, Bergström K, Börjesson S, Greco C, Unnerstad HE, Landén A, Nilsson O, Pringle M, Segerman B, Ågren J: Use of antimicrobials and occurence of antimicrobial resistance in Sweden. SWEDRES-SWARM 2013. Uppsala, 2013

11. Weese JS, van Duijkeren E. Methicillin resistant Staphylococcus aureus and Staphylococcus pseudintermedius in veterinary medicine. Vet Microbiol. 2010;140:418-29.

12. Griffeth GC, Morris DO, Abraham JL, Shofer FS, Rankin SC. Screening for skin carriage of methicillin-resistant coagulase-positive staphylococci and Staphylococcus schleiferi in dogs with healthy and inflamed skin. Vet Dermatol. 2008;19:142-9.

13. Kawakami T, Shibata S, Murayama N, Nagata M, Nishifuji K, Iwasaki T, et al. Antimicrobial susceptibility and methicillin resistance in Staphylococcus pseudintermedius and Staphylococcus schleiferi subsp. coagulans isolated from dogs with pyoderma in Japan. J Vet Med Sci. 2010;72:1615-9.

14. Chanchaithong P, Perreten V, Schwendener S, Tribuddharat C, Chongthaleong A, Niyomtham W, et al. Strain typing and antimicrobial susceptibility of methicillin-resistant coagulase-positive staphylococcal species in dogs and people associated with dogs in Thailand. J Appl Microbiol. 2014;117:572-86.

15. Van Duijkeren E, Box AT, Heck ME, Wannet WJ, Fluit AC. Methicillin-resistant staphylococci isolated from animals. Vet Microbiol. 2004;103:91-7.

16. Feßler AT, Billerbeck C, Kadlec K, Schwarz S. Identification and characterization of methicillin-resistant coagulase-negative staphylococci from bovine mastitis. J Antimicrob Chemother. 2010;65:1576-82.

17. Chah KF, Gomez-Sanz E, Nwanta JA, Asadu B, Agbo IC, Lozano C, et al. Methicillin-resistant coagulase-negative staphylococci from healthy dogs in Nsukka, Nigeria. Braz J Microbiol. 2014;45:215-20.

18. Catry B, van Duijkeren E, Pomba MC, Greko C, Moreno MA, Pyörälä S, et al. Reflection paper on MRSA in food-producing and companion animals: epidemiology and control options for human and animal health. Epidemiol Infect. 2010;138:626-44.

19. Vengust M, Anderson ME, Rousseau J, Weese JS. Methicillin-resistant staphylococcal colonization in clinically normal dogs and horses in the community. Lett Appl Microbiol. 2006;43:602-6.

20. Dubois D, Grare M, Prere MF, Segonds C, Marty N, Oswald E. Performances of the Vitek MS matrix-assisted laser desorption ionization-time of flight mass spectrometry system for rapid identification of bacteria in routine clinical microbiology. J Clin Microbiol. 2012;50:2568-76.

21. Anonymous: Multiplex PCR for the detection of the mecA gene. In: National Food Institute Protocol. Danish Techical University, Copenhagen, 06.02.2008.

22. Sasaki T, Tsubakishita S, Tanaka Y, Sakusabe A, Ohtsuka M, Hirotaki S, et al. Multiplex-PCR method for species identification of coagulase-positive staphylococci. J Clin Microbiol. 2010;48:765-9.

23. Cuny C, Layer F, Strommenger B, Witte W. Rare occurrence of methicillinresistant Staphylococcus aureus CC130 with a novel mecA homologue in humans in Germany. PLoS One. 2011;6(9), e24360.

24. Schnellmann C, Gerber $V$, Rossano A, Jaquier V, Panchaud Y, Doherr MG, et al. Presence of new mecA and $m p h(C)$ variants conferring antibiotic resistance in Staphylococcus spp. isolated from the skin of horses before and after clinic admission. J Clin Microbiol. 2006;44:4444-54.

25. Aarestrup FM, Agerso Y, Gerner-Smidt P, Madsen M, Jensen LB. Comparison of antimicrobial resistance phenotypes and resistance genes in Enterococcus faecalis and Enterococcus faecium from humans in the community, broilers, and pigs in Denmark. Diagn Microbiol Infect Dis. 2000;37:127-37.

26. Jensen LB, Hammerum AM, Bager F, Aarestrup FM. Streptogramin resistance among Enterococcus faecium isolated from production animals in Denmark in 1997. Microb Drug Resist. 2002;8:369-74.

27. Perreten $V$, Vorlet-Fawer L, Slickers $P$, Ehricht $R$, Kuhnert $P$, Frey J. Microarraybased detection of 90 antibiotic resistance genes of gram-positive bacteria. J Clin Microbiol. 2005:43:2291-302.

28. Barros EM, Coetto H, Bastos MCF, Dos Santos KRN, Giambiagi-Demarval M. Staphylococcus haemolyticus as an important hospital pathogen and carrier of methicillin resistance genes. J Clin Microbiol. 2012;50:166-8.

29. Huber H, Ziegler D, Pflüger V, Vogel G, Zweifel C, Stephan R. Prevalence and characteristics of methicillin-resistant coagulase-negative staphylococci from livestock, chicken carcasses, bulk tank milk, minced meat, and contact persons. BMC Vet Res. 2011;7:6. 
30. Zhang Y, Agidi S, LeJeune JT. Diversity of staphylococcal cassette chromosome in coagulase-negative staphylococci from aninam sources. J Clin Appl Microbiol. 2009;107:1375-83.

31. Schwarz S. Emerging chloramphenicol resistance in Staphylococcus lentus from mink following chloramphenicol treatment: characterisation of the resistance genes. Vet Microbiol. 1994:41:51-61.

32. Stepanovic S, Jezek P, Vukovic D, Dakic I, Petras P. Isolation of members of the Staphylococcus sciuri group from urine and their relationship to urinary tract infections. J Clin Microbiol. 2003;41:5262-4.

33. De Martino L, Lucido M, Mallardo K, Facello B, Mallardo M, lovane G, et al. Methicillin-resistant staphylococci isolated from healthy horses and horse personnel in Italy. J Vet Diagn Invest. 2010;22:77-82.

34. Smyth RW, Kahlmeter G. Mannitol salt agar-cefoxitin combination as a screening medium for methicillin-resistant Staphylococcus aureus. J Clin Microbiol. 2005;43:3797-9.

35. Ruzauskas M, Couto N, Siugzdiniene R, Belas A, Klimiene I, Virgailis M, et al. Occurence and characterization of livestock-associated methicillin-resistant Staphylococcus aureus. Vet Med Zoot. 2014;66:58-63.

36. Schissler JR, Hillier A, Daniels JB, Cole LK, Gebreyes WA. Evaluation of Clinical laboratory Standards Institute interpretive criteria for methicillin-resistant Staphylococcus pseudintermedius isolated from dogs. J Vet Diagn Invest. 2009;21:684-8.

37. Ruzauskas M, Siugzdiniene R, Seputiene V, Suziedeliene E, Virgailis M, Daugelavicius $R$, et al. The situation of antimicrobial resistance of enteric bacteria isolated from animal origin to quinolones and fluoroquinolones. Vet Med Zoot. 2010;50:73-80.

38. Ruzauskas M, Siugzdiniene R, Suziedeliene E, Seputiene V, Pavilonis J. Antimicrobial resistance of Enterococcus spp. spread in poultry products in Lithuania. J Food Saf. 2010;30:902-15.

39. Seputiene V, Bogdaite A, Ruzauskas M, Suziedeliene E. Antibiotic resistance genes and virulence factors in Enterococcus faecium and Enterococcus faecalis from diseased farm animals: pigs, cattle and poultry. Pol J Vet Sci. 2012;15:431-8

40. Trzcinski K, Cooper BS, Hryniewicz W, Dowson CG. Expression of resistance to tetracyclines in strains of methicillin-resistant Staphylococcus aureus. J Antimicrob Chemother. 2000;45:2778-81.

41. Małyszko I, Schwarz S, Hauschild T. Detection of a new mecC allotype, mecC2, in methicillin-resistant Staphylococcus saprophyticus. J Antimicrob Chemother. 2014;69:2003-5.

\section{Submit your next manuscript to BioMed Central and take full advantage of:}

- Convenient online submission

- Thorough peer review

- No space constraints or color figure charges

- Immediate publication on acceptance

- Inclusion in PubMed, CAS, Scopus and Google Scholar

- Research which is freely available for redistribution 